\title{
Karakteristik Unjuk Kerja 2 Pompa Sentrifugal Dengan Susunan Seri Sebagai Turbin Pat
}

\author{
Sudirman Lubis ${ }^{1 *}$, Irpansyah Siregar ${ }^{2 * *}$ dan A M Siregar ${ }^{3}$ \\ ${ }^{1,3}$ Program Studi Teknik Mesin, Fakultas Teknik, Universitas Muhammadiyah Sumatera Utara \\ ${ }^{2}$ Program Studi Teknik Mesin, Fakultas Teknik, Universitas Amir Hamzah \\ Email:* sudirmanlubis@umsu.ac.id,**irpansyahsiregar@gmail.com
}

\begin{abstract}
The pump is a device used to move fluid from one place to another through a media pipe or channel. The energy in the fluid is produced from the impeller which converts the kinetic energy (velocity) of the liquid into potential (dynamic) energy. Besides being used to move fluid (fluid) at this time the pump can also be used as a turbine by changing the working principle of the pump by giving a drop of water at an altitude to rotate the impeller on the pump so that the pump can operate upside down or called a pump as turbine), in this study the impeller on the pump as a turbine is driven by a water flow or water pressure that is large enough, the water flow is sourced from two centrifugal pumps with a series arrangement that functions as a driving force or fluid distributor which is assumed to be a high water fall or head. The use of centrifugal pumps with a series arrangement is so as to produce a large head to get a high water fall or a maximum head for turning a pump as a turbine. This study uses an experimental method that is using two centrifugal pumps as a fluid distributor and one pump that is used as a turbine and uses a variation of 5 watt and 10 watt light bulb. From the calculation of the suction pump and pump as a turbine without using a light bulb pump speed namely $920.5 \mathrm{rpm}$ and the specific speed of the turbine produced is $76.61 \mathrm{rpm}$. by using a 5 watt light bulb load the pump rotation speed is $553 \mathrm{rpm}$ and the specific turbine speed produced is $44.24 \mathrm{rpm}$, using a 10 watt light bulb load the pump rotation speed is $335 \mathrm{rpm}$ and the specific turbine speed produced is $26.8 \mathrm{rpm}$. The greater the value of the pump head, the resulting water discharge will be smaller and vice versa, the size and size of the pump head obtained is also influenced by the presence of load on theturbine.
\end{abstract}

Keywords: Compact Heat Exchanger, Vortex Generator, Curve Delta Winglet, Solidworks Flow Simulation

\section{PENDAHULUAN}

Pompa adalah alat yang digunakan untuk memindahkan cairan (fluida) darisuatu tempat ketempat yang lain melalui media pipa atau saluran dengan cara menambahkan energi pada cairan yang dipindahkan. Energi pada fluida dihasilkan dari impeller yang merubah energi kinetis (kecepatan) cairan memutar impeller, hal tersebut menggambarkan bahwa tidak lagi menggunakan tinggi jatuh air, tetapi data spesifikasi dari pompa tersebut merupakan tinggi jatuh yang diasumsikan sebagai menjadi energi potensial (dinamis). Fluida yang masuk kedalam pompa akan mengalami pertambahan energi, pertambahan energi pada fluida akan mengakibatkan pertambahan debit aliran, daya, head, dan efisiensi pompa (Surya Agus Pratama: 2017).

Pada saat ini selain digunakan untuk memindahkan cairan (fluida) pompa juga digunakan sebagai alternatif yang bisa digunakan sebagai turbin, dimana pada pompa sebagai turbin ini secara mekanik digerakan oleh fluida pada suatu ketinggian atau head untuk memutar pompa sehingga pompa tersebut dapat beroprasi terbalik atau disebut dengan Pump As Turbine(PAT).

Pemanfaatan pompa merupakan pilihan yang ekonomis untuk dijadikan turbin, pompa yangdimaksud telah banyak tersedia dipasaran dan diproduksi dalam jumlah yang besar, harga yang relatif terjangkau dan tersedia dalam berbagai ukuran dan variasi. Bertambahnya permintaan energi yang memperhatikan faktor lingkungan dan aspek ekologi menjadikan penggunaan pompa 
sebagai turbin sebagai inovasi tepat guna untuk dijadikan turbin. hal ini dapat membantu untuk mengatasi krisis energi listrik dan juga mendukung program pemerintah untuk memanfaatkan energi terbarukan yang ramah lingkungan yang dapat dikembangkan untuk mengatasi semakin meningkatnya penggunaan energi listrik.

Untuk merealisasikan head atau tinggi jatuh air beberapa eksperimen menggunakan pompa sebagai tenaga pendorong atau penyalur fluida yang akan disalurkan terhadap pompa sebagai turbin untuk memutar impeller, hal tersebut menggambarkan bahwa tidak lagi menggunakan tinggi jatuh air, tetapi data spesifikasi dari pompa tersebut merupakan tinggi jatuh yang diasumsikan sebagai tinggi jatuh air atau head untuk menggerakan pompa sebagai turbin. Dalam memaksimalkan tinggi jatuh tersebut maka dapat dilakukan dengan menghubungkan beberapa buah pompa yang disusun secara seri karena susunan seri dalam susunan pompa adalah untuk menghasilkan head yang besar untuk mendapatkan ketinggian maksimal

Berdasarkan uraian diatas maka penulis tertarik untuk mengetahui "Karakteristik Unjuk Kerja Pompa Sebagai Turbin (Pat) Dengan Debit Air Masuk Menggunakan 2 Pompa Sentrifugal Dengan Susunan Seri"

\section{TEORI}

\section{PengertianPompa}

Pompa beroprasi dengan prinsip membuat perbedaan tekan antara bagian hisap (suction) dengan bagian tekan (discharge). Dengan kata lain pompa berfungsi mengubah tenaga mekanis dari sumber tenaga (penggerak) menjadi tenaga kinetis (kecepatan), dimana energi ini berguna untuk mengalirkan fluida dan mengatasi hambatan yang ada sepanjang pengaliran. Pada industriindustri banyak menggunakan pompa sebagai salah satu peralatan bantu yang penting untuk proses produksi, salah satunya untuk mensirkulasi air atau minyak pelumas atau pendingin mesin-mesin industri (Mechanical Engineering: 2011)

\section{Klasifikasi Pompa}

\section{Positive Displacement Pump (Pompa PerpindahanPositif)}

Pompa perpindahan positif adalah perpindahan zat cair dari suatu tempat ketempat yang lain yang disebabkan oleh adanya perubahan volume ruang kerja pompa yang diakibatkan oleh gerakan elemen pompa yaitu bolak-balik atau berputar. Pompa jenis ini disebut dengan pompa aksi positif yaitu energi mekanik dari putaran poros pompa yang diubah langsung menjadi energi potensial, pompa jenis ini menghasilkan head yang tinggi tetapi kapasitas yang dihasilkan rendah (Satrio Utomo: 2016).

a. PompaRotary

Pompa rotary ini memindahkan fluida kerja melalui mekanisme rotary dengan jalan menimbulkan efek vakum sehingga dapat menghisap fluida kerja dari sisi inlet, dan memindahkannya ke sisi outlet. Terperangkapnya udara didalam rotary, secara natural pompa ini akan mengeluarkan udara tersebut. Jenis pompa rotary antara lain, pompa roda gigi, pompa screw, dan pompakipas.

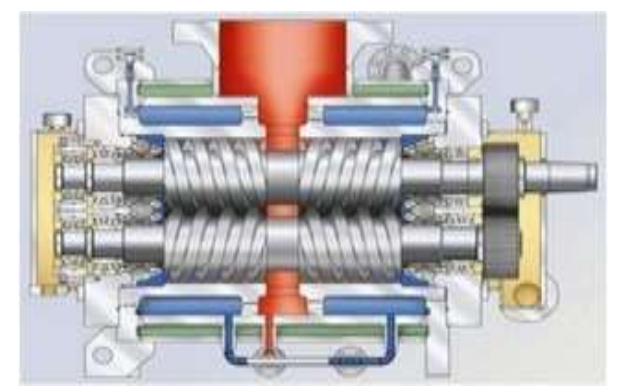

Gambar 1. Pompa Rotary

Copyright ${ }^{\odot} 2020$ Jurnal Rekayasa Material, Manufaktur dan Energi. This is an open acces article under the CC-BY-SA lisence (https://creativecommons.org/licenses/by-sa/4.0/). 


\section{Jurnal Rekayasa Material, Manufaktur dan Energi}

b. Pompareciprocating

Pompa ini menggunakan piston yang bergerak maju mundur sebagai komponen kerjanya, serta mengarahkan aliran fluida kerjanya satu arah dengan check valve. Pompa reciprocating ini memiliki rongga kerja yang meluas pada saat menghisap fluida dan akan mendorong dengan mempersempit rongga kerja tersebut. Check valve digunakan untuk mengatur arah aliran fluida sehingga akan terjadi proses pemompaan yangseimbang.

\section{Klasifikasi PompaSentrifugal}

Pompa sentrifugal dapat diklasifikasikan, berdasarkan :

1. kapasitas:

Kapasitas rendah $<20 \mathrm{~m}^{3} / \mathrm{jam}$

Kapasitas rendah $20-60 \mathrm{~m}^{3} / \mathrm{jam}$

Kapasitas rendah $>60 \mathrm{~m}^{3} / \mathrm{jam}$

2. Tekanan Discharge:

Kapasitas rendah $<5 \mathrm{~kg} / \mathrm{m}^{2}$

Kapasitas rendah $5-50 \mathrm{~kg} / \mathrm{m}^{2}$

Kapasitas rendah > $50 \mathrm{~kg} / \mathrm{m}^{2}$ (Mechanical Engineering:2011)

\section{PengertianFluida}

Fluida merupakan zat cair yang dapat berubah bentuk secara terus menerus jika terkena tegangan geser meskipun tegangan geser tersebut kecil. Fluida lebih mudah mengalir karena ikatan molekul dalam fluida lebih kecil dari ikatan molekul dalam zat padat, akibatnya fluida mengalami hambatan yang relatif kecil pada perubahan bentuk karena gesekan (Aya Snura: 2012).

\section{AliranLaminar}

Didalam aliran laminar partikel-partikel zat cair bergerak teratur mengikuti lintasan yang saling sejajar. Aliran laminar lebih mudah terjadi bila aliran relatif kecil sedangkan viskositas cairan besar dan pengaruh kekentalan cukup dominan dibandingkan dengan kecepatan aliran, sehingga partikel-partikel zat cair akan bergerak teratur mengikuti lintasan lurus (Aya Snura: 2012)

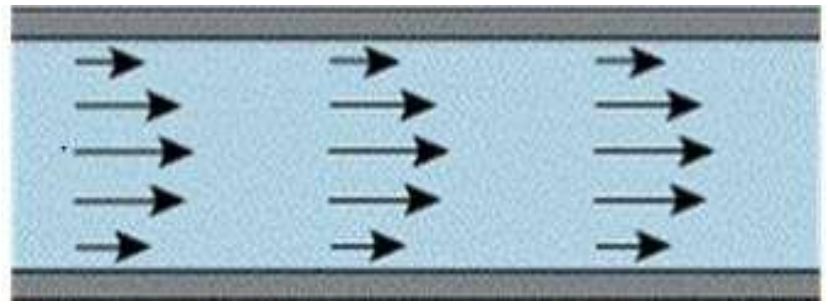

Gambar 2. Aliran Laminar

\section{AliranTurbulen}

Aliran turbulen adalah gerakan partikel zat cair yang tidak teratur antara satu dengan yang lain dan sembarang dalam waktu dan ruang. Turbulensi ditimbulkanolehgaya-gaya viskos dan gerak lapis zat cair yang berdampingan pada kecepatan berbeda. Karakteristik aliran turbulen ditunjukan oleh terbentuknya pusaran-pusaran dalam aliran yang menghasilkan percampuran partikel-partikel secara terus menerus antara partikel-partikel 


\section{Jurnal Rekayasa Material, Manufaktur dan Energi}

cairan didalam seluruh penampang aliran.

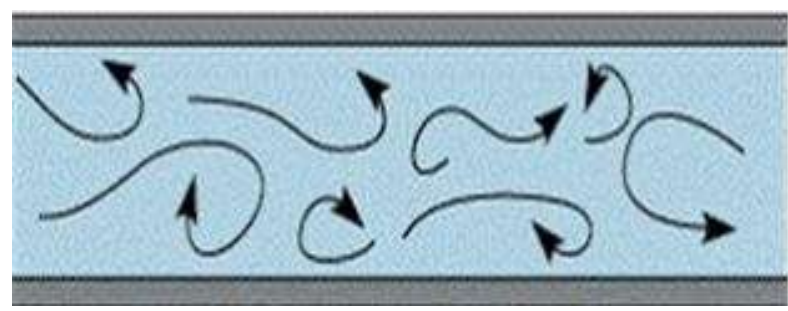

Gambar 3. Aliran Turbulen

\section{Head Kerugian Gesek Pada Sambungan Elbow $90^{\circ}$ DalamPipa}

Kerugian minor adalah kehilangan tekanan yang disebabkan oleh adanya gesekan yang terjadi pada katub-katub, sambungan belokan dan pada luas penampang yang tidak tetap. Fluida yang melewati belokan dan katub head loss minor tersebut dapat dihitung dengan persamaan berikut:

$h 1_{1}=n k_{1} \frac{v^{2}}{2 g}$

Dimana: $n=$ Jumlah sambungan $90^{\circ}$

$\mathrm{k} 1=$ Faktor kelengkungan pipa lekuk $90^{\circ}=1,129($ Lampiran tabel $)$ kerugian belokan pipa).

$\mathrm{V}=$ Kecepatan aliran dalam pipa $(\mathrm{m} / \mathrm{s})$

$\mathrm{g}=$ Percepatan gravitasi $(\mathrm{m} / \mathrm{s})$

\section{Head Kerugian Gesek Pada Katup Isap Dengan Saringan}

Kerugian ini dapat dilihat dengan persamaanberikut:

$h 1_{2}=n k_{1} \frac{v^{2}}{2_{g}}$

Dimana: $\mathrm{k}=$ faktor akibat adanya katup isap dengan saringan $=1.97$ (Lampiran table kerugian dari berbagai katup isap dengan saringan) .

$\mathrm{V}=$ Kecepatan aliran dalam pipa $(\mathrm{m} / \mathrm{s})$

$\mathrm{g}=$ Percepatan gravitasi $(\mathrm{m} / \mathrm{s})$

\section{Turbin Air}

Turbin air adalah salah satu mesin berputar yang mengkonversi energi dari suatu gerakan aliran air (fluida) menjadi energi mekanis. Dengan memanfaatkan aliran dan tinggi jatuh air, fluida yang bergerak menjadikan sudu pada turbin berputar dan menghasilkan energi untuk menggerakan rotor, air dibawah tekanan tinggi didalam dan dilepaskan kedalam suatu saluran dimana akan menggerakan impeler turbin sehingga menyebabkan putaran yang cepat (Faqih Fadilah: 2015). Komponen-komponen utama pada turbin air terdiri dari rotor dan stator, rotor merupakan bagian yang berputar pada sistem turbin, sedangkan stator merupajan bagian yang diam pada sistem turbin air.

\section{Alternator}

Altenator adalah suatu alat elektromekanikal yang mengkonversi daya mekanis menjadi energi elektrik. Pada prinsipnya generator dapat juga disebut sebagi altenator, tetapi biasanya 


\section{Jurnal Rekayasa Material, Manufaktur dan Energi}

altenator lebih mengacu pada bentuk yang lebih kecil yang biasa digunakan pada otomotif (Teli Handayani). Altenator memiliki 4 bagian yang penting

\section{Pengatur Tegangan}

Pada bagian ini dapat mengontrol jumlah voltase yang diberikan oleh altenator. Arus yang dihasilkan pada altenator dapat diperoleh dengan dua cara yaitu, magnet berputar didalam coil (lilitan) atau coil berputar pada medan magnet yang diciptakan oleh magnet. Besarnya arus yang dihasilkan oleh altenator tergantung pada kecepatan baling-baling, kekuatan medan magnet, dan ukuran dari coil.

Semakin tegaklurus medan magnet terhadap lilitan coil, maka semakin besar arus elektrik dan keluaran energinya

\section{METODE PENELITIAN}

Penelitian ini menggunakan metode eksperimental, yaitu dengan melakukan serangkaian pengujian terhadap pompa yang meliputi debit, daya, head, dan efisiensi pompa sebagai dasar dari penggerak utama pompa sebagai turbin (PAT).

\section{HASIL DAN PEMBAHASAN}

Hasil Dan Pembahasan Grafik Pada Pompa Sebagai Turbin

Tabel 1 Data Hasil Pengujian

\begin{tabular}{cccccccccc}
\hline $\begin{array}{c}\text { Beban } \\
(\text { Watt })\end{array}$ & $\begin{array}{c}\text { Debit } \\
\left(\mathbf{m}^{\mathbf{3}} / \mathbf{s}\right)\end{array}$ & $\begin{array}{c}\mathbf{N} \\
(\mathbf{r p m})\end{array}$ & $\begin{array}{c}\mathbf{V} \\
(\mathbf{v o l t})\end{array}$ & $\begin{array}{c}\mathbf{I} \\
(\mathbf{a})\end{array}$ & $\begin{array}{c}\mathbf{H} \\
(\mathbf{m})\end{array}$ & $\begin{array}{c}\mathbf{P}_{\text {in }} \\
(\text { Watt })\end{array}$ & $\begin{array}{c}\mathbf{P}_{\text {out }} \\
(\text { Watt })\end{array}$ & $\begin{array}{c}\mathbf{\eta} \\
(\boldsymbol{\%})\end{array}$ & $\begin{array}{c}\mathbf{N q} \\
(\mathbf{r p m})\end{array}$ \\
\hline $\mathbf{0}$ & 0,000188 & 920,5 & 18,85 & 0 & 1,76 & 2871,27 & 0 & 0 & 76,61 \\
$\mathbf{5}$ & 0,00021 & 553 & 8,76 & 1,02 & 1,68 & 2661,6 & 8,9 & 0,33 & 44,24 \\
$\mathbf{1 0}$ & 0,000255 & 335 & 4,45 & 1,48 & 2,22 & 4174,8 & 6,58 & 0,15 & 26,8 \\
\hline
\end{tabular}

\section{Grafik data variasi dengan bebanlampu}

Dari perbandingan hasil grafik data variasi dengan beban lampu diketahui bahwa hasil efesiensi nilai tertinggi yang didapatkan sebesar $0,33 \%$ pada Debit $0.00021 \mathrm{~m}^{3} / \mathrm{s}$, Nilai Head sebesar $=1,68 \mathrm{~m}$ dan kecepatan spesifik turbin $(\mathrm{Nq})=26,8 \mathrm{rpm}$ dan menghasilkan daya keluaran sebesar 6,58 Watt

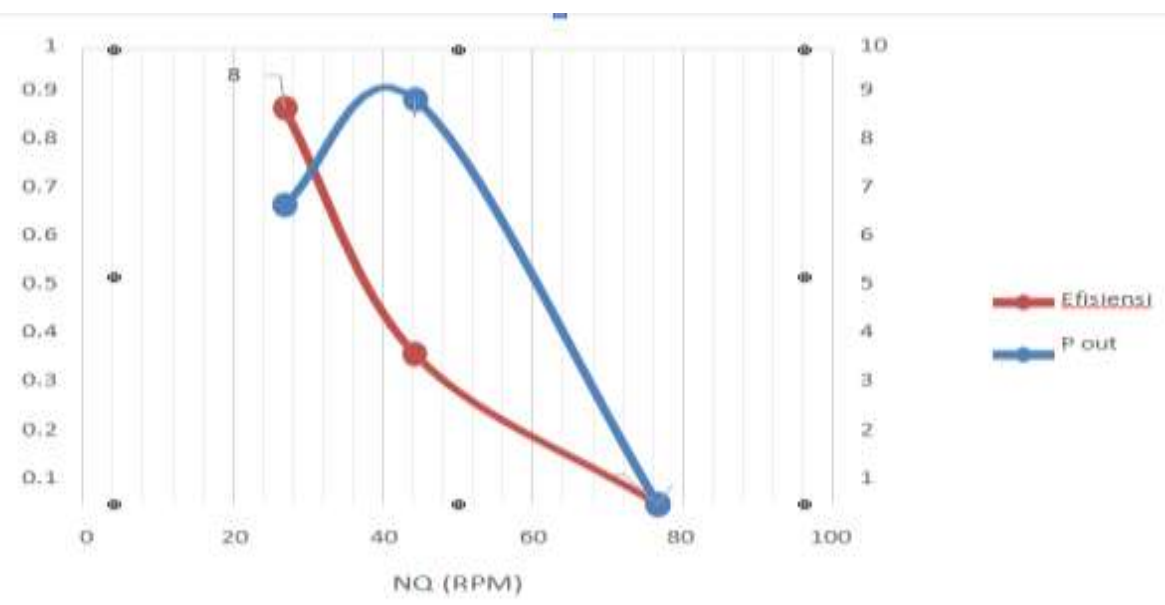

Gambar 4. Grafik data variasi dengan beban lampu

Copyright $^{\circledR} 2020$ Jurnal Rekayasa Material, Manufaktur dan Energi. This is an open acces article under the CC-BY-SA lisence (https://creativecommons.org/licenses/by-sa/4.0/). 


\section{Efisiensi pompa sebagai turbin}

Dari perbandingan grafik Efisiensi dengan kecepatan spesifik turbin $(\mathrm{Nq})$ dari seluruh pembebanan, dapat dilihat nilai efisiensi tertinggi sebesar $0,33 \%$ pada putaran turbin $=44,24 \mathrm{rpm}$.

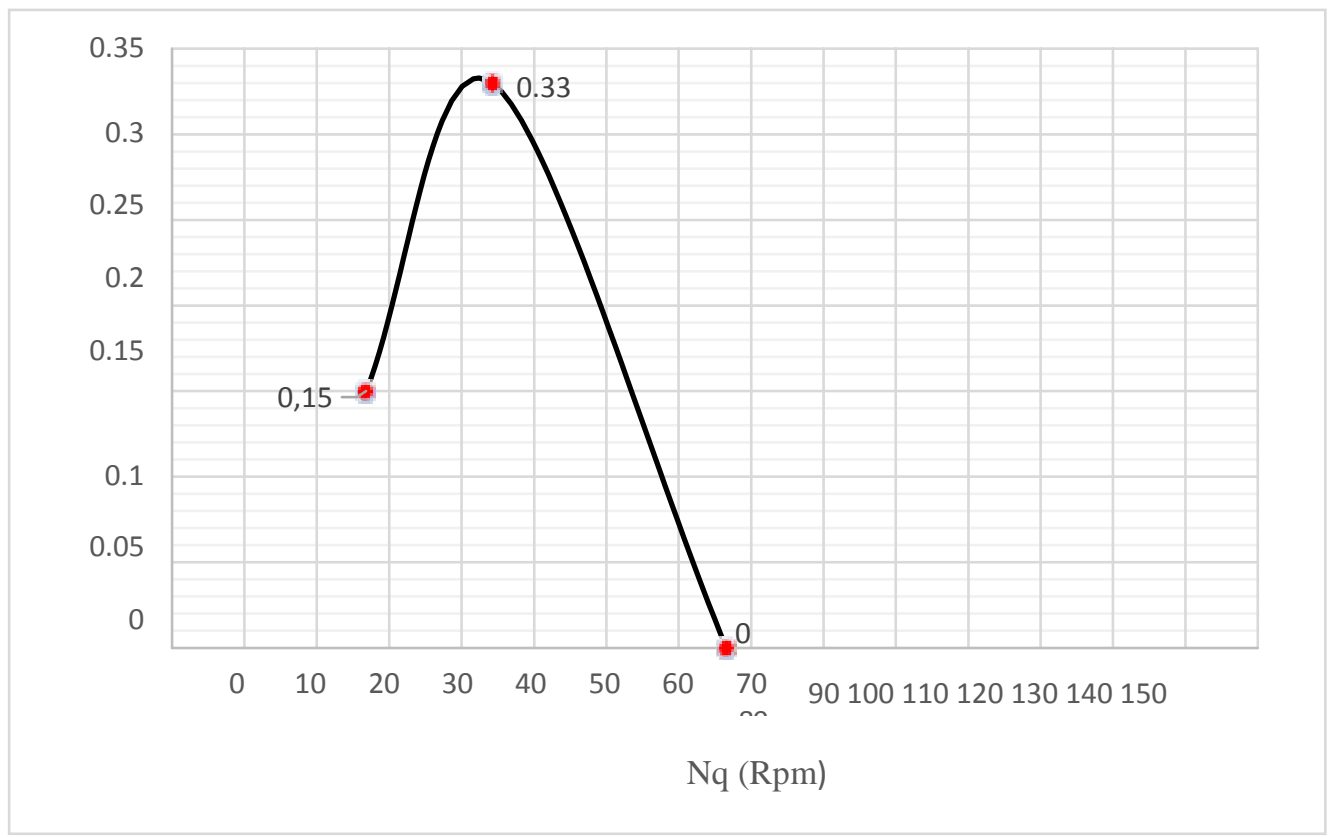

Gambar 5. Grafik Efisiensi vs Nq

\section{Karakteristik pompa sebagai turbin yangdiuji}

Dari perbandingan grafik Debit, Head dengan $\mathrm{Nq}$, dapat dilihat nilai $\mathrm{Nq}$ tertinggi sebesar $=$ $76,61 \mathrm{rpm}$ pada $\mathrm{Head}=1,76 \mathrm{~m}$ dan debit terbesar yaitu $0,000255 \mathrm{~m}^{3} /$ detik

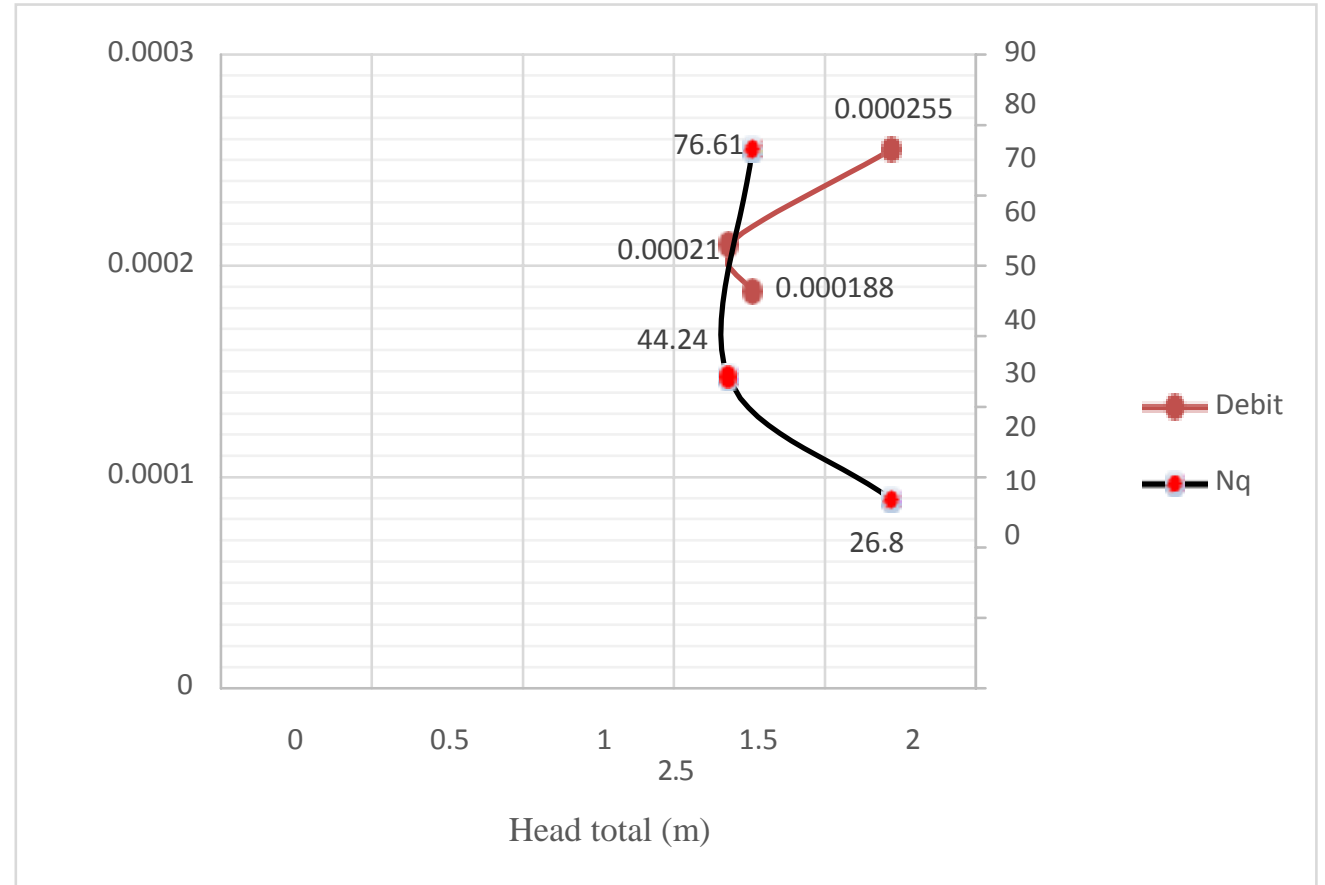

Gambar 6. Grafik Debit, Head dan Nq 


\section{KESIMPULAN}

1. Dari hasil perhitungan pompa hisap dan pompa sebagai turbin tanpa menggunakan beban bola lampu kecepatan putaran pompa yaitu 920,5 rpm dan kecepatan spesifik turbin yang dihasilkan adalah 76,61 rpm. dengan spesifik turbin yang dihasilkan 44,24 rpm. dengan menggunakan beban bola lampu 10 watt kecepatan putaran pompa sebesar $335 \mathrm{rpm}$ dan kecepatan spesifik turbin yang dihasilkan adalah 26,8rpm.

2. Semakin besar nilai head pompa, maka debit air yang dihasilkan akan semakin kecil begitu juga sebaliknya, besar dan kecilnya menggunakan beban bola lampu 5 watt kecepatan putaran pompa sebesar $553 \mathrm{rpm}$ dan kecepatan head pompa yang didapatkan juga dipengaruhi oleh adanya pemberian beban padaturbin.

3. Semakin besar nilai head pompa, maka debit air yang dihasilkan akan semakin kecil begitu juga sebaliknya, besar dan kecilnya menggunakan beban bola lampu 5 watt kecepatan putaran pompa sebesar $553 \mathrm{rpm}$ dan kecepatan head pompa yang didapatkan juga dipengaruhi oleh adanya pemberian beban padaturbin

\section{SARAN}

Mengingat masih terbuka lebar untuk penelitian selanjutnya mengenai pompa sebagai turbin maka beberapa masukan berikut ini bisa menjadi pertimbangan

1. Penelitian dengan menggunakan variasi impeller yang berbeda.

2. Menggunakan pompa hisap dengan kapasitas yang lebih besar untuk memperoleh kinerja pompa sebagai turbin yang lebih baik

\section{DAFTA PUSTAKA}

[1] Asep Rachmat, Ali Hamdani, (2007). Pembangkit Listrik Metode Pump As Turbunes. Jurnal J-Ensitec: vol 03 no 02. Teknik Mesin, Fakultas Teknik, Universitas Majalengka.

[2] Aya Snura, (2012). Aliran fluida dalam pipa, dikutip dari http://aya-snura.blogspot.com.

[3] Christian Asri Wicaksana, Fakih Fadilah (2015) makalah Turbin Air, Teknik Mesin, Fakultas Teknik Universitas Malang, Malang.

[4] Digilib.polban.ac.id/files/disk1/71/jbptppolban-gdlaseparifnu-Pump As Turbine.

[5] Himsar Ambarita, (2011). Kajian Eksperimental Performansi Pompa Dengan Kapasitas $1,25 \mathrm{~m} / \mathrm{menit}$ Head $12 \mathrm{~m}$ Jika Dioprasikan Sebagai Turbin, Departemen Teknik Mesin Fakultas Teknik USU, Medan, Sumatera Utara. https://Journals.itb.ac.id/index.php/jtms/article/download/4909/2685.

[6] Mechanical Engineering, (2011). Pompa (рump), dikutip dari http://mechanicmechanicalengeneering.blogspot.com/2011/03/pompa;pump.html?m=1.

[7] Satrio Utomo, (2016). Defenisi pompa dan klasifikasi pompa, dikutip dari http://satrioutomo2016.blogspot.com/2017/02/defenisi-pompa-dan-klasifikasipompa.html?m=1,

[8] Sularso, Haruo Tahara,(2000). Pompa \& Kompresor, pemilihan, pemakaian, dan pemeliharaan, cetakan ketujuh, jakarta. Pradnya Paramita.

[9] Surya Agus Pratama, (2017). Analisa Kinerja Aliran Fluida Pada Pompa Sentrifugal Dengan Variasi Panjang Sudu Impeller. Jurnal Teknik Mesin, Medan: Program Studi Teknik Mesin, UMSU.

[10] Teli Handayani, (2007). Prestasi Pompa Sentrifugal Dengan Impeller Tertutup Sebagai Turbin Air, Laporan Tugas Akhir, Yogyakarta: Program Studi Teknik Mesin, Universitas Sanata Dharma Yogyakarta.

[11] Termudi, (2016). Bilangan Reynolds dan Lapisan Batas (Boundary Layer), dikutip dari http://turmudikemiri.blogspot.com/2016/01/bilangan-reynolds-reynolds-numberdan.html?m=1diakes pada 23 november2019. 
Vol. 3, No. 2, September 2020, Halaman 85-92

ISSN 2622-7398

DOI:https://doi.org/10.30596/rmme.v3i2.5270 $\quad$ http://jurnal.umsu.ac.id/index.php/RMME Jurnal Rekayasa Material, Manufaktur dan Energi

[12] Yuliani, (2017). Analisa Perbandingan Kinerja Pompa Sentrifugal Dengan Pengaturan Bukaan Katup, Jurnal Sainstek STT Pekan baru, Vol 5, No 2 